\title{
A fuzzy AHP based integer linear programming model for the multi-criteria transshipment problem
}

\author{
Ting He* \\ Research Centre of Intelligent Computing for Enterprises and Services, \\ Harbin Institute of Technology, Harbin, China 150001 \\ William Ho \\ Operations and Information Management Group, \\ Aston Business School, Aston University, Birmingham B4 7ET, United Kingdom \\ Carman Ka Man Lee \\ Department of Industrial and Systems Engineering \\ The Hong Kong Polytechnic University \\ Hung Hom, Kowloon, Hong Kong
}

\begin{abstract}
Purpose - The purpose of this research is to develop a holistic approach to maximize the customer service level while minimizing the logistics cost by using an integrated multiple criteria decision making (MCDM) method for the contemporary transshipment problem. Unlike the prevalent optimization techniques, this paper proposes an integrated approach which considers both quantitative and qualitative factors in order to maximize the benefits of service deliverers and customers under uncertain environment.

Design/methodology/approach - This paper proposes a fuzzy-based integer linear programming model, based on the existing literature and validated with an example case. The model integrates the developed fuzzy modification of the analytic hierarchy process (FAHP), and solves the multi-criteria transshipment problem.
\end{abstract}

Findings - This paper provides several novel insights about how to transform a company from a cost-based model to a service dominated model by using an integrated MCDM method. It suggests that the contemporary customer-driven supply chain remains and increases its competitiveness from two aspects: optimizing the cost and providing the best service simultaneously.

Research limitations/implications - This research used one illustrative industry case to exemplify the developed method. Considering the generalization of the research findings and the complexity of the transshipment service network, more cases across multiple industries are necessary to further enhance the validity of the research output.

Practical implications - The paper includes implications for the evaluation and selection of transshipment service suppliers, the construction of optimal transshipment network as well as managing the network. 
Originality/value - The major advantages of this generic approach are that both quantitative and qualitative factors under fuzzy environment are considered simultaneously and also the viewpoints of service deliverers and customers are focused. Therefore, it is believed that it is useful and applicable for the transshipment service network design.

Keywords Transshipment problem; multiple criteria decision making; integer linear programming; fuzzy analytic hierarchy process (FAHP).

Paper Type Research paper

* Corresponding author. 


\section{Introduction}

The contemporary transshipment problems have become one of the most popular and important issues not only in the land logistics and the air logistics, but also in the marine logistics. It is an extension of the transportation problem which is a critical area of supply chain and logistics management that may lead to cost reductions and improved services for companies to make higher profits and to become more competitive. For the transportation problem, it is assumed that a commodity can only be shipped from an origin to a destination. In many real-life situations, it is also possible to distribute the commodity through the points of origins or through the points of destinations. Sometimes, it might be advantageous to distribute a commodity from an origin to an intermediate or a transshipment point before shipping it to a destination. The transshipment problem allows for these shipments.

Traditionally, a network that incurs the lowest total distribution cost or requires the minimum total delivery distance was regarded as an optimal solution to the transshipment problem (Winston, 2003). However, this kind of network cannot enhance the competitive advantages of companies in nowadays. Besides focusing on quantitative factors, sufficient attention must be paid to the qualitative factors such as customer service or satisfaction.

In the contemporary supply chain management theory, maximization of customer service level is as important as minimization of costs/distance for a company to make profit and increase competitiveness. Customer service level can be measured by various quantitative and qualitative elements, including product delivery time, customer response time, consistency of order cycle time, accuracy of order fulfillment rate, flexibility in order quantity, flexibility in product specification, ability to respond to market changes, risks management level, and so on (Ballou, 2004; Kengpol, 2008). The higher the customer service level, the higher the probability for customers to repeat orders and for companies to win market shares. Undoubtedly, both viewpoints of deliverer and customer must be considered in designing an optimal distribution network in the contemporary supply chain management.

In this paper, an improved and generalized integer linear programming (ILP) model was formulated to solve the problem of multi-criteria transshipment service network design. The model, which integrates the fuzzy set theory and analytic hierarchy process (AHP), is to minimize logistics costs of company and maximize service level of its customers under uncertain situations. Unlike the prevalent cost-based or precision-based optimization techniques, the proposed approach considers both quantitative and qualitative factors and also aims at maximizing the benefits of deliverer and customers. This can help the supply chain to reduce costs, increase efficiency and flexibility, enhance the satisfaction level of customers 
and its own competitiveness is therefore improved.

\section{Literature review}

For the multi-criteria decision making (MCDM) problems, many precision-based or fuzzy-based MCDM techniques have been proposed in recent years, including mathematical programming, heuristic algorithms, and other different methods. Here, the "precision" refers to the concept of accurate measure and crisp evaluation, whereas the "fuzzy" means uncertain or vague measure and evaluation.

One of the most prominent MCDM techniques is AHP (Ho, 2009) developed by Saaty (1980) which is a general theory of measurement. Saaty (1990) stated that it can be used to derive ratio scales from both discrete and continuous paired comparisons in multi-level hierarchical structures. AHP, especially integrated AHP, have been widely used in the decision-making process by academics and practitioners (Korpela and Tuominen, 1996; Kengpol and Tuominen, 2006; Ho et al., 2008) in the last 20 years. Ho (2008) reviewed the literature of AHP and its applications from 1997 to 2006.

Owing to the wide applicability, ease of use and great flexibility of AHP, some researchers (Korpela \& Lehmusvaara, 1999; Korpela, Lehmusvaara, \& Tuominen, 2001a, Korpela, Kyläheiko, Lehmusvaara, \& Tuominen, 2001b, 2002; Bertolini, Bevilacqua, 2006; Kengpol, 2008; Ho, 2009) have constructed the combined AHP-mixed integer linear programming (MILP) model and the combined AHP-mixed goal programming (GP) model approaches for the logistics distribution network design, whereas another group of researchers (Chan \& Chung, 2004a, 2004b, 2005; Chan, Chung \& Wadhwa, 2004, 2005; Chan, Chung \& Choy, 2006) applied the combined AHP-genetic algorithm (GA) approaches to solve the problem.

Under certain situations, the values for the qualitative criteria of the MCDM problems are often imprecisely defined for the decision maker. It is not easy to precisely quantify the rating of each alternative and the precision based methods as stated above are not adequate to deal with the logistics distribution optimization problem (Chen, 2000). Since human judgments including preference are often vague and cannot estimate his preference with an exact numerical value. A more realistic way is to use linguistic terms to describe the desired value and important weight of criteria, e.g. “very low”, “medium”, “high”, “fair”, “very high", etc. Due to this type of existing fuzziness in the distribution optimization process, fuzzy set theory is an appropriate method to deal with uncertainty, and the subjective evaluation data can be more adequately expressed in fuzzy linguistic variables. Fuzzy set 
theory was developed exactly based on the premise that the key elements in human thinking are not numbers, but linguistic terms or labels of fuzzy sets (Bellman and Zadeh, 1970). Hence, some researchers have attempted to use the fuzzy logic based MCDM methods for logistics distribution problem recently. For example, Önüt and Soner (2008) presented a fuzzy TOPSIS based method to solve the solid waste transshipment site selection problem. Chou (2007, 2010) used a fuzzy multiple criteria decision-making (FMCDM) model to evaluate and select the container transshipment hub port.

In addition, there were some other different MCDM methods developed. Malchow et al. (2004) used an alternative form of the discrete choice model to analyze and evaluate the distribution of maritime shipments among US ports which formed a disaggregate analysis method of port selection. Farahani (2007) proposed a multiple objective decision making technique to locate some warehouses as distribution centers in a real-world military logistics system which aimed to minimize the cost of locating the facilities and maximize the quality of the distribution center (DC) locations. Chan et al. (2007) presented a fuzzy integrated hierarchical decision-making approach to solve the DC location selection problem. Tabari et al. (2008) proposed a hybrid MCDM method to select the optimal location that satisfies the decision maker. With the aid of fuzzy AHP, this model considered objective, critical, and subjective factors as the three main common factors in location analysis. Chou et al. (2008) conducted a fuzzy simple additive weighting system under group decision-making for facility location selection with objective/subjective attributes. Sharma and Jana (2009) presented a transshipment planning model for the petroleum refinery industry. The main objective of the model is to minimize the total transshipment cost, maximize production, satisfy storage requirements at depots, and meet the demand for oil in these sales areas.

To complement the presentation of the most relevant papers in this field, Table 1 summarizes the characteristics of the prevalent MCDM models and methods from the literature above. It can be seen that none of these models except the method proposed by this article concerns all the six characteristics so that there are some deficiencies or limitations in application. For example, some MCDM methods (Refs [7,12-14,16-18,20-21] in Table 1) were based on the deliverer's benefit priority instead of improving the customer's satisfaction. Therefore, it is believed that the designed distribution network may not be customer effective. For some other approaches (Refs [1-11,19] in Table 1), the evaluation criteria used in AHP are all quantitative such as total cost, total delivery day, effectiveness of capacity utilization for warehouses, and so on whereas the qualitative factors such as flexibility of capacity and value-added services were neglected. These factors are crucial in the integrated logistics 
system because they affect the customer satisfaction directly.

Table 1 The literate review of the MCDM methods and their characteristics

\begin{tabular}{|c|c|c|c|c|c|c|c|}
\hline Refs & Authors & $\begin{array}{c}\text { Precision- } \\
\text { based }\end{array}$ & $\begin{array}{l}\text { Fuzzy } \\
\text {-based }\end{array}$ & $\begin{array}{c}\text { Supplier's } \\
\text { benefit }\end{array}$ & $\begin{array}{c}\text { Customer's } \\
\text { benefit }\end{array}$ & $\begin{array}{c}\text { Quantitative } \\
\text { factors }\end{array}$ & $\begin{array}{l}\text { Qualitative } \\
\text { factors }\end{array}$ \\
\hline 1 & Korpela et al.(1999) & $\sqrt{ }$ & & $\sqrt{ }$ & $\sqrt{ }$ & $\sqrt{ }$ & $\sqrt{ }$ \\
\hline 2 & Korpela et al.(2001a) & $\sqrt{ }$ & & $\checkmark$ & $\sqrt{ }$ & $\sqrt{ }$ & $\sqrt{ }$ \\
\hline 3 & Korpela et al.(2001b) & $\sqrt{ }$ & & & $\sqrt{ }$ & $\sqrt{ }$ & $\sqrt{ }$ \\
\hline 4 & Korpela et al.(2002) & $\sqrt{ }$ & & & $\sqrt{ }$ & $\sqrt{ }$ & $\sqrt{ }$ \\
\hline 5 & Chan \& Chung (2004a) & $\sqrt{ }$ & & $\sqrt{ }$ & $\sqrt{ }$ & $\sqrt{ }$ & $\sqrt{ }$ \\
\hline 6 & Chan \& Chung (2004b) & $\sqrt{ }$ & & $\sqrt{ }$ & $\sqrt{ }$ & $\sqrt{ }$ & $\sqrt{ }$ \\
\hline 7 & Malchow (2004) & $\sqrt{ }$ & & $\sqrt{ }$ & & $\sqrt{ }$ & $\sqrt{ }$ \\
\hline 8 & Chan \& Chung (2005) & $\sqrt{ }$ & & $\checkmark$ & $\sqrt{ }$ & $\checkmark$ & $\sqrt{ }$ \\
\hline 9 & Chan, et al., (2005) & $\sqrt{ }$ & & $\sqrt{ }$ & $\sqrt{ }$ & $\sqrt{ }$ & \\
\hline 10 & Bertolini, et al. (2006) & $\sqrt{ }$ & & $\sqrt{ }$ & $\sqrt{ }$ & $\sqrt{ }$ & $\sqrt{ }$ \\
\hline 11 & Chan, et al., (2006) & $\sqrt{ }$ & & $\sqrt{ }$ & $\sqrt{ }$ & $\sqrt{ }$ & \\
\hline 12 & Chou (2007) & $\sqrt{ }$ & $\sqrt{ }$ & $\sqrt{ }$ & & $\sqrt{ }$ & $\sqrt{ }$ \\
\hline 13 & Farahani (2007) & $\sqrt{ }$ & & $\sqrt{ }$ & & $\sqrt{ }$ & \\
\hline 14 & Chan (2007) & $\checkmark$ & $\sqrt{ }$ & $\sqrt{ }$ & & $\sqrt{ }$ & $\sqrt{ }$ \\
\hline 15 & Kengpol (2008) & $\sqrt{ }$ & & $\sqrt{ }$ & $\sqrt{ }$ & $\sqrt{ }$ & $\sqrt{ }$ \\
\hline 16 & Önüt and Soner (2008) & $\sqrt{ }$ & $\sqrt{ }$ & $\sqrt{ }$ & & $\sqrt{ }$ & $\sqrt{ }$ \\
\hline 17 & Tabari (2008) & $\sqrt{ }$ & $\sqrt{ }$ & $\sqrt{ }$ & & $\sqrt{ }$ & $\sqrt{ }$ \\
\hline 18 & Chou (2008) & $\sqrt{ }$ & $\sqrt{ }$ & $\sqrt{ }$ & & $\sqrt{ }$ & $\sqrt{ }$ \\
\hline 19 & Но (2009) & $\sqrt{ }$ & & $\sqrt{ }$ & $\sqrt{ }$ & $\sqrt{ }$ & $\sqrt{ }$ \\
\hline 20 & Sharma (2009) & & $\sqrt{ }$ & $\sqrt{ }$ & & $\sqrt{ }$ & $\sqrt{ }$ \\
\hline 21 & Chou (2010) & $\sqrt{ }$ & $\sqrt{ }$ & $\sqrt{ }$ & & $\sqrt{ }$ & $\sqrt{ }$ \\
\hline 22 & This paper & $\sqrt{ }$ & $\sqrt{ }$ & $\sqrt{ }$ & $\sqrt{ }$ & $\checkmark$ & $\sqrt{ }$ \\
\hline
\end{tabular}

According to the above literature review, a better decision support model is needed to improve decision making on a transshipment service network design. The quantitative and qualitative criteria under fuzzy environment should be included to achieve maximum customer satisfaction with minimum logistics cost. Thus, this paper attempts to present a new fuzzy AHP based ILP model for the multi-criteria transshipment problem which differs from the literature is to synthesize the advantages of the literature (all the 6 characteristics) while overcoming their disadvantages.

Fig. 1 shows the procedures of the proposed model. First, analyze the multi-criteria 
transshipment problem, then the evaluation criteria of the transshipment candidates that customers consider most important are given and subsequently define the goal problem. According to the criteria, the required data utilized in the comparisons are collected from the related customers again. After constructing the evaluation criteria hierarchy, the criteria weights are calculated by applying the fuzzy AHP method. The performances of the alternatives corresponding to the criteria are performed under the setting of fuzzy set theory. Finally, the ILP model is employed to achieve the cost oriented final ranking results.

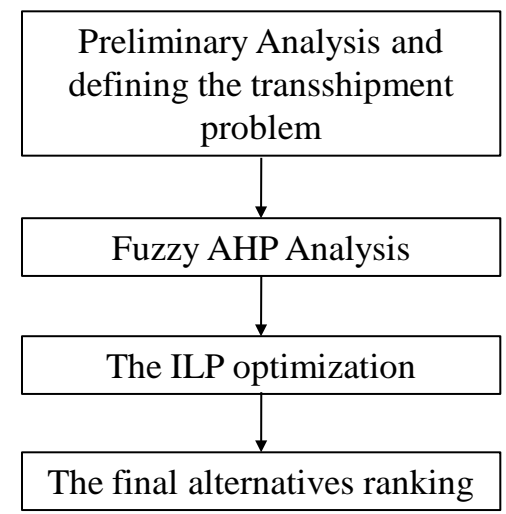

Fig. 1 The overall procedures of the fuzzy-AHP based ILP model

The rest of this paper is organized as follows. Section 3 discusses the idea of the fuzzy-AHP based ILP model (FAHP-ILP). Section 4 explains the adoption of the fuzzy AHP in this proposed multi-criteria transshipment model. Section 5 analyzes the computation results. Finally, section 6 contains the conclusions and directions for future research.

\section{A multi-criteria transshipment problem}

This paper introduces one of our partners in the automotive industry in China as an illustrative example. This partner is interested in assessing its new transshipmemt management strategy by using our method which attempts to transform it from a cost effective company to a service dominant one. Therefore, we obtain the relevant information as an illustrative example which consists of two manufacturing plants, four warehouses, and five customers (see Fig. 2). Here, the customers mean the company's automobile 4S (Sale, Sparepart, Service and Survey) shops. 


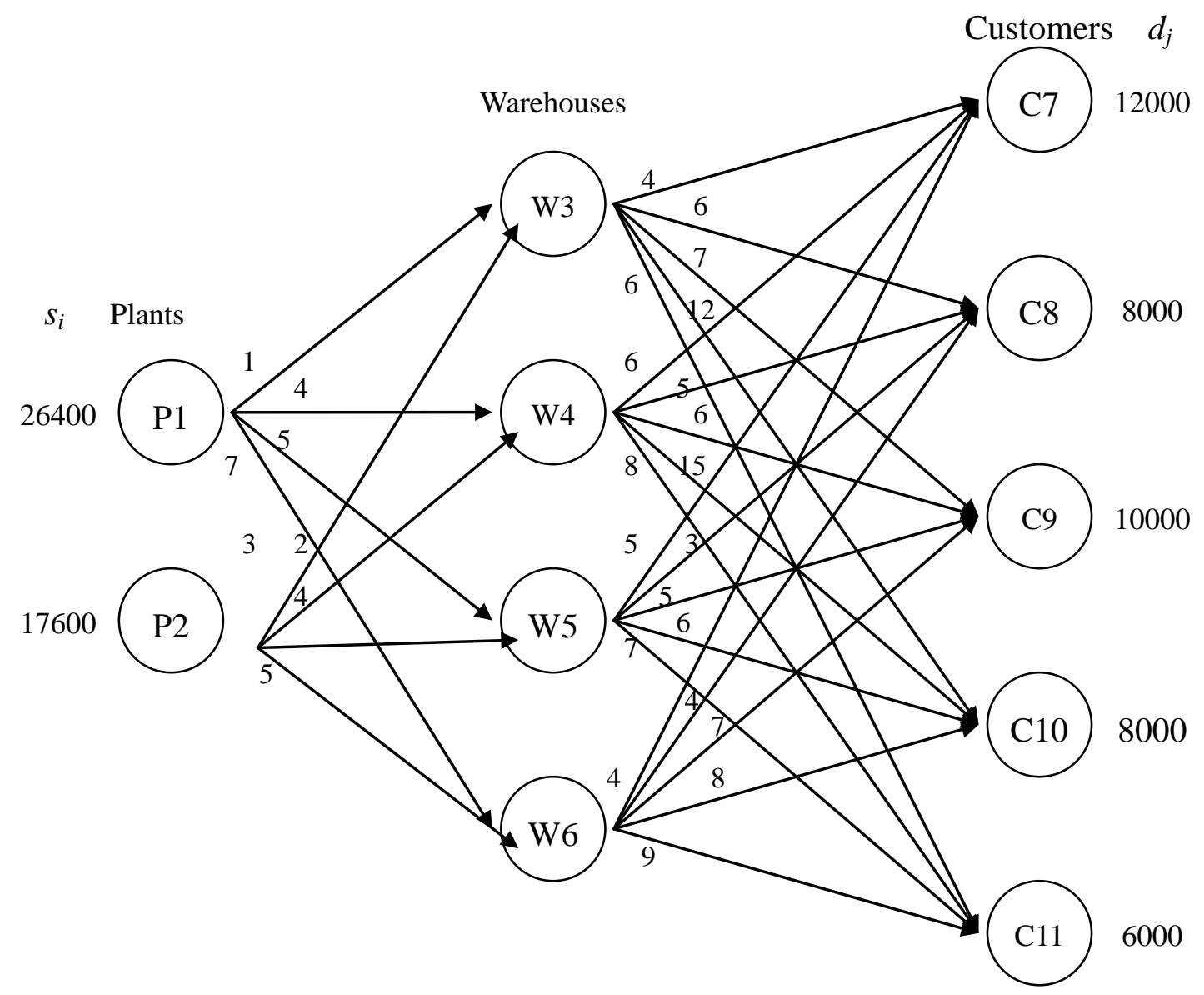

Fig. 2 The transshipment network of the collaborated automotive company

For the purpose of later comparison, this paper firstly develops the cost-based transshipment model originally adopted by our auto-company partner. This company has a number of plants each of which has a limited available capacity, $s_{i}$. After manufacturing, the semi-finished products are delivered to the warehouses for final assembly and packaging. Finally, the finished products are shipped to the customers according to their requirements, $d_{j}$. The problem is how to fulfill each customer's order while not exceeding the capacity of any plant at minimum cost, $c_{i j}$. The problem can be transformed as a conventional transportation model with $(n-b)$ origins and $(n-a)$ destinations, where $n$ is the total number of nodes in the network (i.e., total number of plants, warehouses, and customers), $a$ is the number of node that has supply only or so-called "pure origin", and $b$ is the number of node that has demand only or so-called “pure destination”. Any node that has both supply and demand is referred to as a transshipment point. The unit transportation costs, $c_{i j}$, are often dependent on the travel distances between node $i$ to node $j$. It is assumed that the cost on a particular route of the network is directly proportional to the amount of products shipped on that route. If there is no route connecting node $i$ and node $j$ or arc $(i, j)$ does not exist, the cost is assigned to be 
infinite $(\infty)$. The cost of delivering one unit of product from node $i$ to itself is zero. By introducing decision variables $x_{i j}$ to represent the amount of product sent from node $i$ to node $j$, the cost-based transshipment model originally adopted by our auto-company partner can be written as

Model 3.1 A cost-based transshipment model

$$
\text { Minimize } \mathrm{z}=\sum_{i=1}^{n-b} \sum_{j=a+1}^{n} c_{i j} x_{i j}
$$

subject to

$$
\begin{array}{ll}
\sum_{j=a+1}^{n} x_{i j}=s_{i} & i=1,2, \ldots, a \\
\sum_{j=a+1}^{n} x_{i j}=S & i=a+1, a+2, \ldots, n-b \\
\sum_{i=1}^{n-b} x_{i j}=S & j=a+1, a+2, \ldots, n-b \\
\sum_{i=1}^{n-b} x_{i j}=d_{j} & j=n-b+1, n-b+2, \ldots, n \\
\text { All } x_{i j} \geq 0 &
\end{array}
$$

From the viewpoint of the previous cost-based transportation optimization (Winston, 2003; Kumar et al., 2011), Model 3.1 is referred to as a typical cost-based transshipment problem model. Objective function (3-1) is to minimize the total cost. Constraint set (3-2) is an availability constraint for the pure origin nodes $(i=1,2, \ldots, a)$, whereas constraint set (3-3) is an availability constraint for the transshipment nodes $(i=a+1, a+2, \ldots, n-b)$. It is assumed that all origin nodes supply the transshipment nodes. Therefore, each transshipment node will have a supply equals the total available supply, $S$. Constraint set (3-4) is a requirement constraint for the transshipment nodes $(j=a+1, a+2, \ldots, n-b)$, whereas constraint set (3-5) is a requirement constraint for the pure destination nodes $(j=n-b+1, n$ $-b+2, \ldots, n)$. For constraint set (3-5), if a customer also acts as a transshipment node, he will have a demand equals to the summation of its original demand and total available supply (i.e., $d_{j}+S$ ).

In the contemporary studies on service dominant supply chains, the logistics distribution network design is influenced by both deliverer and customers under fuzzy environment. Focusing on either maximization of company's profit or maximization of customers' satisfaction level is not the best way to optimize the logistics distribution problem. 
In the following, a multi-criteria transshipment model is proposed to select an optimal set of warehouses and to determine an optimal product allocation under limitations of resources. The objective function is the minimization of the total logistics cost, in which the fuzzy based AHP priorities of warehouses are incorporated as weighting factors. Those warehouses with higher AHP priorities have higher probabilities of being selected. In the other words, the objectives of the multi-criteria transshipment model are to minimize the total cost of the company while at the same time maximize the satisfaction level of its customers under uncertain situations.

In this case, each plant has a limited available capacity (i.e., $s_{i}$ ), whereas each customer has a unique order volume (i.e., $d_{j}$ ). The warehouses can be regarded as the transshipment points, each of which has a minimum throughput (i.e., $q_{i}$ ), a fixed cost (i.e., $f c_{i}$ ), and a unit inventory holding cost (i.e., $h c_{i}$ ). When plant/warehouse $i$ is assigned to serve warehouse/customer $j$, it costs $d c_{i j}$ yuan per unit for delivery, which are shown above the arcs in Figure 2. If the total amount of products assigned to warehouse $i$ (i.e., $\sum_{j=1}^{n} x_{i j} \forall i$ ) is less than $q_{i}$, this is regarded as impractical allocation because it is not cost-effective to set up a warehouse for processing only a few orders. To avoid low effectiveness of warehouse utilization, penalty cost (i.e., $p c_{i}$ ) is considered in the model, which is incurred if $0<\sum_{j=1}^{n} x_{i j}<q_{i}$. The notation used in the integrated FAHP-ILP model is listed in Table 2. The multi-criteria transshipment model can be written as

Model 3.2 FAHP-ILP model for the multi-criteria transshipment problem

$$
\text { Minimize } z=\sum_{i=1}^{n-b} \sum_{j=a+1}^{n} w f_{j}\left(h c_{j}+d c_{i j}\right) x_{i j}+\sum_{i=a+1}^{n-b} w f_{i} f c_{i} v_{i}+\sum_{i=a+1}^{n-b} w f_{i} p c_{i} w_{i}
$$

subject to

$$
\begin{array}{ll}
\sum_{j=a+1}^{n} x_{i j}=s_{i} & i=1,2, \ldots, a \\
\sum_{j=a+1}^{n} x_{i j}=S & i=a+1, a+2, \ldots, n-b \\
\sum_{i=1}^{n-b} x_{i j}=S & j=a+1, a+2, \ldots, n-b
\end{array}
$$




$$
\begin{array}{ll}
\sum_{i=1}^{n-b} x_{i j}=d_{j} & j=n-b+1, n-b+2, \ldots, n \\
\sum_{j=n-b+1}^{n} x_{i j}+M u_{i} \geq q_{i} & i=a+1, a+2, \ldots, n-b \\
\sum_{j=n-b+1}^{n} x_{i j}-M v_{i} \leq 0 & i=a+1, a+2, \ldots, n-b \\
w_{i}-u_{i}-v_{i}=-1 & i=a+1, a+2, \ldots, n-b \\
x_{i j} \geq 0 \text { and is } a \text { set of integers } & \\
u_{i}, v_{i}, \text { and } w_{i}=0 \text { or } 1 &
\end{array}
$$

Table 2 Notations used in the integrated FAHP-ILP model

\footnotetext{
Indices:

$i, j=$ nodes (i.e., manufacturing plants, warehouses, and customers)

$n=$ total number of nodes in the transshipment network

$a=$ number of nodes that have supply only or so-called "pure origin"

$b=$ number of nodes that have demand only or so-called "pure destination"
}

\section{Data:}

$s_{i}=$ supply of plant $i$

$d_{j}=$ demand of customer $j$

$S=$ total available supply

$q_{i}=$ minimum throughput of warehouse $i$

$f c_{i}=$ fixed cost associated with selecting warehouse $i$

$h c_{i}=$ unit inventory holding cost of warehouse $i$

$p c_{i}=$ penalty cost associated with selecting warehouse $i$

$d c_{i j}=$ unit delivery cost from plant/warehouse $i$ to warehouse/customer $j$

$w p_{i}=$ AHP priority of warehouse $i$

$w f_{i}=$ weighting factor of warehouse $i$

$M=$ arbitrary large number

\section{Decision variables:}

$x_{i j}=$ amount of products delivered from plant/warehouse $i$ to warehouse/customer $j$

$u_{i}=$ zero-one variable ( 1 if the total allocation to warehouse $i$ is less than $q_{i}, 0$ otherwise)

$v_{i}=$ zero-one variable ( 1 if warehouse $i$ is selected, 0 otherwise)

$w_{i}=$ zero-one variable ( 1 if both $\mathrm{u}_{\mathrm{i}}$ and $v_{i}$ are one, 0 otherwise)

Model 3.2, a modified and holistic model for our auto-company partner, is a pure 
integer linear programming model. Objective function (3-6) is to minimize the total weighted logistics cost, including fixed setup cost, inventory holding cost, product delivery cost, and penalty cost. The weighting factors for each warehouse (i.e., $w f_{i}$ ) are computed using equation (3-14):

$$
w f_{i}=\frac{\sum_{i=1}^{m} w p_{i}-w p_{i}}{\sum_{i=1}^{m} w p_{i} \times(m-1)}
$$

Based on the above equation, the amount of $w f_{i}$ is inversely proportional to that of $w p_{i}$ (FAHP priority of warehouse $i$ ). Better warehouses will have smaller $w f_{i}$, and thus lower weighted total cost. Constraint sets (3-7) to (3-10) are the same as constraint sets (3-2) to (3-5), respectively. Constraint sets (3-11) to (3-12) are used to examine whether the product allocation is practical or not. Penalty cost (i.e., $p c_{i}$ ) will be incurred if $0<\sum_{j=1}^{n} x_{i j}<q_{i}, \forall i$.

\section{Fuzzy analytic hierarchy process}

To solve the Model 3.2, the values of warehouse $i$ priorities $\left(w p_{i}\right)$ and the weighting factors for warehouse $i\left(w f_{i}\right)$ should be firstly computed. FAHP, as a widely used decision-making method in many application fields under uncertain environments (Meixner, 2003), is employed to compute them.

\subsection{The analytic hierarchy process}

The AHP is a multi-attribute decision tool that allows financial and non-financial, quantitative and qualitative measures to be considered and trade-offs among them to be addressed. It aims to integrate different measures into a single overall score for ranking decision alternatives (Saaty, 1980). It consists of four following sequenced operations including hierarchy construction, local priorities assessment, global priorities calculation, and consistency verification.

First, the AHP decision problem is structured hierarchically at different levels, each level consisting of a finite number of decision elements. The top level of the hierarchy represents the overall goal, while the lowest is composed of all alternatives. One or more intermediate levels embody the decision criteria and sub-criteria.

Second, the relative importance of the decision elements (weights of criteria and scores of alternatives) is assessed from comparison judgments during the priority analysis of AHP operations. The decision-maker is required to provide his/her subjective judgments by 
comparing all criteria, sub-criteria and alternatives with respect to upper level decision elements. The values of the weights and scores of alternatives are elicited from these comparisons and represented in a decision table. The global priorities calculation aggregates all local priorities from the decision table by a simple weighted sum. The global priorities thus obtained are used for final ranking of the alternatives and selection of the best one. Here, subjective judgment can be depicted using quantitative scales which are usually divided into 9-point scale, shown in Table 3, to enhance the transparency of decision making process.

Table 3 The AHP comparison scale

\begin{tabular}{ccl}
\hline Intensity & Importance & \multicolumn{1}{c}{ Explanation } \\
\hline 1 & Equal & Two activities contribute equally to the object \\
3 & Moderate & $\begin{array}{l}\text { Slightly favors one over another } \\
\text { Strongly favors one over another }\end{array}$ \\
7 & Strong & $\begin{array}{l}\text { Dominance of the demonstrated in practice } \\
9\end{array}$ \\
Very strong & Extreme & Evidence favoring one over another of highest possible order \\
& of affirmation \\
$2,4,6,8$ & Intermediate & When compromise is needed \\
Reciprocals of the above numbers & For inverse comparison \\
\hline
\end{tabular}

Because the comparisons are carried out through personal or subjective judgments, some degree of inconsistency may occur. To guarantee that the judgments are consistent, the final operation called consistency verification, which is regarded as one of the greatest advantages of the AHP, is incorporated to measure the degree of consistency among the pairwise comparisons by computing the consistency ratio $(C R)$. If it is found that the amount of $C R$ exceeds the limit or 0.10 , the decision makers should review and revise the pairwise comparisons.

\subsection{The fuzzy analytic hierarchy process - FAHP}

The standard AHP cannot be directly applied to solving uncertain decision-making problems (Mikhailov, 2004). In order to eliminate this limitation, the triangular fuzzy membership function and its fuzzy arithmetic operations are introduced in the AHP to fuzzify and calculate the pairwise comparison results, and thus the traditional AHP becomes the fuzzy AHP or FAHP (Meixner, 2009).

For the latter estimation of the importance of warehouse evaluation criteria, we use the FAHP method. Let $\tilde{A}$ represent a fuzzified reciprocal $n \cdot n$-judgment matrix containing all 
pairwise comparisons between elements $i$ and $j$ for all $i, j \in\{1,2, \ldots, n\}$

$$
\tilde{A}=\left[\begin{array}{cccc}
\tilde{a}_{11} & \tilde{a}_{12} & \cdots & \tilde{a}_{1 n} \\
\tilde{a}_{21} & \tilde{a}_{22} & \cdots & \tilde{a}_{2 n} \\
\vdots & \vdots & \ddots & \vdots \\
\tilde{a}_{n 1} & \tilde{a}_{n 2} & \cdots & \tilde{a}_{n n}
\end{array}\right]
$$

Where $\tilde{a}_{i j}=\tilde{a}_{i j}{ }^{-1}$ and all are triangular fuzzy numbers $\tilde{a}_{i j}=\left(l_{i j}, m_{i j}, u_{i j}\right)$ with $l_{i j}$ the lower and $u_{i j}$ the upper limit and $m_{i j}$ is the point where the membership function $\mu(x)=1$. The membership function $\mu(x)$ of the triangular fuzzy number may therefore be described as (Chang, 1996):

$$
\mu(x)=\left\{\begin{array}{cc}
0 & x<l \\
(x-l)(m-l) & l \leq x \leq m \\
(u-x)(u-m) & m \leq x \leq u \\
0 & x>u
\end{array}\right.
$$

Where $l$ denotes the probable minimum value of all the pairwise comparison result, $m$ is the most probable value, and $u$ is the probable maximum value. If $l=m=u$, the fuzzy number gets a crisp number.

For the two triangular fuzzy numbers $\tilde{F}_{1}=\left(l_{1}, m_{1}, u_{1}\right)$ and $\tilde{F}_{2}=\left(l_{2}, m_{2}, u_{2}\right)$ with the principle proposed by Zadeh (1965) and the features of triangular fuzzy numbers presented by Liang and Wang (1991), the extended algebraic operations on triangular fuzzy numbers can be expressed as follows:

$$
\begin{array}{ll}
\text { Addition: } & \tilde{F}_{1} \oplus \tilde{F}_{2}=\left(l_{1}+l_{2}, m_{1}+m_{2}, u_{1}+u_{2}\right) \\
\text { Multiplication: } & \tilde{F}_{1} \otimes \tilde{F}_{2}=\left(l_{1} * l_{2}, m_{1} * m_{2}, u_{1} * u_{2}\right) \\
\text { Division: } & \tilde{F}_{1} \div \tilde{F}_{2}=\left(l_{1} / u_{2}, m_{1} / m_{2}, u_{1} / l_{2}\right) \\
\text { Reciprocal: } & \frac{1}{\tilde{F}_{1}}=\left(\frac{1}{u_{1}}, \frac{1}{m_{1}}, \frac{1}{l_{1}}\right)
\end{array}
$$

The triangular fuzzy numbers are easy to use and interpret. In the fuzzy AHP, Saaty’s 9-point scale of AHP (Saaty, 1995) should be made a shift accordingly which presents the linguistic variables and their corresponding triangle fuzzy numbers shown in Table 4. 
Table 4 Linguistic variables and their corresponding triangle fuzzy numbers

\begin{tabular}{cccc}
\hline $\begin{array}{c}\text { Triangle fuzzy } \\
\text { number }\end{array}$ & Linguistic variable & $\begin{array}{c}\text { Triangle fuzzy } \\
\text { number }\end{array}$ & Linguistic variable \\
\hline$(1,1,1)$ & Equal & $(1.5,2,2.5)$ & Between equal and moderate \\
$(2.5,3,3.5)$ & Moderate & $(3.5,4,4.5)$ & Between moderate and strong \\
$(4.5,5,5.5)$ & Strong & $(5.5,6,6.5)$ & Between strong and very strong \\
$(6.5,7,7.5)$ & Very strong & $(7.5,8,8.5)$ & Between very strong and extreme \\
$(9,9,9)$ & Extreme & & \\
\hline
\end{tabular}

As to the triangular fuzzy numbers which are continuous weights, this paper employs the popular center of gravity method (Driankov et al., 1996) to defuzzify them using equation (4-7).

$$
F=\int x * \mu(x) d_{x} / \int \mu(x) d_{x}
$$

Based on the above, this paper develops a new fuzzy modification of the AHP which procedures are as follows.

Step 1: $\quad$ Fuzzy-based AHP pairwise comparison

Construct a fuzzy pairwise comparison matrix

$$
\tilde{A}=\left[\begin{array}{cccc}
\tilde{a}_{11} & \tilde{a}_{12} & \cdots & \tilde{a}_{1 n} \\
\tilde{a}_{21} & \tilde{a}_{22} & \cdots & \tilde{a}_{2 n} \\
\vdots & \vdots & \ddots & \vdots \\
\tilde{a}_{n 1} & \tilde{a}_{n 2} & \cdots & \tilde{a}_{n n}
\end{array}\right]=\left[\begin{array}{cccc}
(1,1,1) & \tilde{a}_{12} & \cdots & \tilde{a}_{1 n} \\
\tilde{a}_{21} & (1,1,1) & \cdots & \tilde{a}_{2 n} \\
\vdots & \vdots & \ddots & \vdots \\
\tilde{a}_{n 1} & \tilde{a}_{n 2} & \cdots & (1,1,1)
\end{array}\right]
$$

where $n$ denotes the number of elements, and $\tilde{a}_{i j}$ refers to the fuzzy comparison number of element $i$ to element $j$ with respect to each criterion. The 9-point scale, shown in Table 4, can be used to decide on which element is more important and by how much.

Step 2: $\quad$ Fuzzy-based AHP synthesization

Divide each entry $\left(\tilde{a}_{i j}\right)$ in each column of matrix $\tilde{A}$ by its column summation. The matrix now becomes a normalized pairwise comparison matrix, 


$$
\tilde{A}^{\prime}=\left[\begin{array}{cccc}
\frac{\tilde{a}_{11}}{\sum_{i \in R} \tilde{a}_{i 1}} & \frac{\tilde{a}_{12}}{\sum_{i \in R} \tilde{a}_{i 2}} & \cdots & \frac{\tilde{a}_{1 n}}{\tilde{a}_{21} \tilde{a}_{i n}} \\
\frac{\tilde{a}_{22}}{\sum_{i \in R} \tilde{a}_{i 1}} & \sum_{i \in R} \tilde{a}_{i 2} & \cdots & \frac{\tilde{a}_{2 n}}{\tilde{\sigma}_{i \in R} \tilde{a}_{i n}} \\
\vdots & \vdots & \ddots & \vdots \\
\frac{\tilde{a}_{n 1}}{\sum_{i \in R} \tilde{a}_{i 1}} & \frac{\tilde{a}_{n 2}}{\sum_{i \in R} \tilde{a}_{i 2}} & \cdots & \frac{\tilde{a}_{n n}}{\sum_{i \in R} \tilde{a}_{i n}}
\end{array}\right]
$$

where $R$ denotes the set of corresponding elements, i.e., $R=\{1,2, \ldots, n\}$.

Step 3: Compute the average of the entries in each row of matrix $\tilde{A}^{\prime}$ to yield column vector,

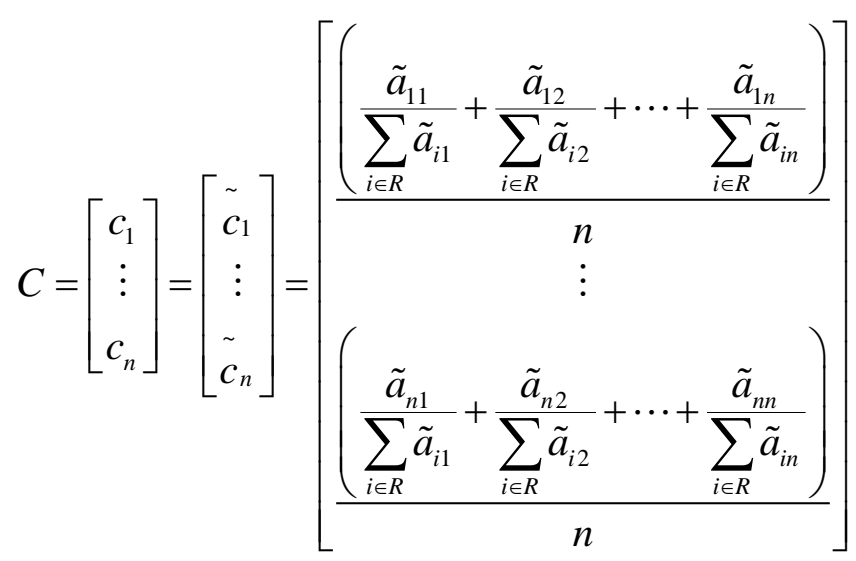

where $c_{i}$ and $\tilde{c}_{1}$ denote the crisp weighting and fuzzy weighting of element $i$ respectively. Here and the following, the equation (4-7) is used to defuzzify the relevant fuzzy triangular numbers.

Step 4: $\quad$ Fuzzy-based AHP consistency verification

Multiply each entry in column $i$ of matrix $\tilde{A}$ by $c_{i}$. Then, divide the summation of values in row $i$ by $c_{i}$ to yield another column vector,

$$
\bar{C}=\left[\begin{array}{c}
\bar{c}_{1} \\
\vdots \\
\overline{c_{n}}
\end{array}\right]=\left[\begin{array}{c}
\frac{c_{1} \tilde{a}_{11}+c_{2} \tilde{a}_{12}+\cdots c_{n} \tilde{a}_{1 n}}{c_{1}} \\
\vdots \\
\frac{c_{1} \tilde{a}_{n 1}+c_{2} \tilde{a}_{n 2}+\cdots c_{n} \tilde{a}_{n n}}{c_{n}}
\end{array}\right]
$$

where $\bar{C}$ refers to a weighted sum vector.

Step 5: Compute the averages of values in vector $\bar{C}$ to yield the maximum eigenvalue of matrix $\tilde{A}$, 


$$
\lambda_{\max }=\frac{\sum_{i \in R} \bar{c}_{i}}{n}
$$

Step 6: Compute the consistency index,

$$
C I=\frac{\lambda_{\max }-n}{n-1}
$$

Step 7: Compute the consistency ratio,

$$
C R=\frac{C I}{R I(n)}
$$

where $R I(n)$ is a random index of which the value is dependent on the value of $n$, shown in Table 5. If $C R$ is greater than 0.10 , then go to step 1 and reconstruct the fuzzy pairwise comparison matrix.

Table 5 List of random index values

\begin{tabular}{ccccccccc}
\hline$n$ & 2 & 3 & 4 & 5 & 6 & 7 & 8 & 9 \\
\hline$R I(n)$ & 0 & 0.58 & 0.90 & 1.12 & 1.24 & 1.32 & 1.41 & 1.45 \\
\hline
\end{tabular}

Comparing with the known fuzzy prioritization methods in the AHP (Boender et al., 1989; Chang, 1996; Xu, 2000; Mikhailov, 2004), it can be observed that the FAHP improved by this study does not require an additional fuzzy ranking procedure for comparing the final scores and ranking alternatives and can derive the local and global crisp priorities directly. This point is very important, because different ranking procedures often give different ranking results (Gonus and Boucher, 1997; Mikhailov, 2004).

\section{Numerical example of FAHP}

For the multi-criteria transshipment problem of our partner introduced in Section 3, the transshipment decision-maker has to select a warehouse. Based on consultation with our collaborative company and with reference to the publications of Ballou (2004) and Kengpol (2008), five criteria have been chosen to evaluate the performance of alternative warehouses. They include value-added services, total lead time, reliability of order fulfillment, flexibility of capacity, and quality. Their meanings and measurement measures are described below.

(1) Value-added services refer to any activities that facilitate customers (e.g., track-and-trace and 24-hour customer hotline) and the responsiveness of warehouses to customer special requests (e.g., secure packaging and urgent delivery). The measurement calculation is in qualitative data: very high, high, medium, low, very low. 
(2) Total lead time comprises the time of handling inventory in warehouses, the time of storing/loading inventory in warehouses and the time of delivering products from warehouses to customers. The measurement is in time scale e.g. 1, 1.5, 2, 2.5, 3 or more days, etc.

(3) Reliability of order fulfillment consists of the accuracy of quantity fulfillment, the accuracy of due date fulfillment, and reliability of delivery time. The measurement calculation is in qualitative: very high, high, medium, low, very low.

(4) Flexibility of capacity refers to the ability of warehouses to respond to fluctuation in volume of customer orders. The measurement calculation is in qualitative data: very high, high, medium, low, very low.

(5) Quality involves the commitment of deliverer to provide high-quality products and the condition of products received by customers. It is also called the transshipment intact rate. The measurement calculation is in percentage, e.g. $<95 \%$, $>95 \%$ and $<96 \%,>96 \%$ and $<97 \%$, $>97 \%$ and $<98 \%,>98 \%$ and $<99 \%,>99 \%$ and $<100 \%, 100 \%$. For the different types of materials, the measurement calculation of intact rate is different in percentage.

The solution process is based on the proposed fuzzy modification of the AHP method. The first step in applying the FAHP is to construct a (three level) hierarchy of alternative warehouses and criteria for choice, as shown in Figure 3. 


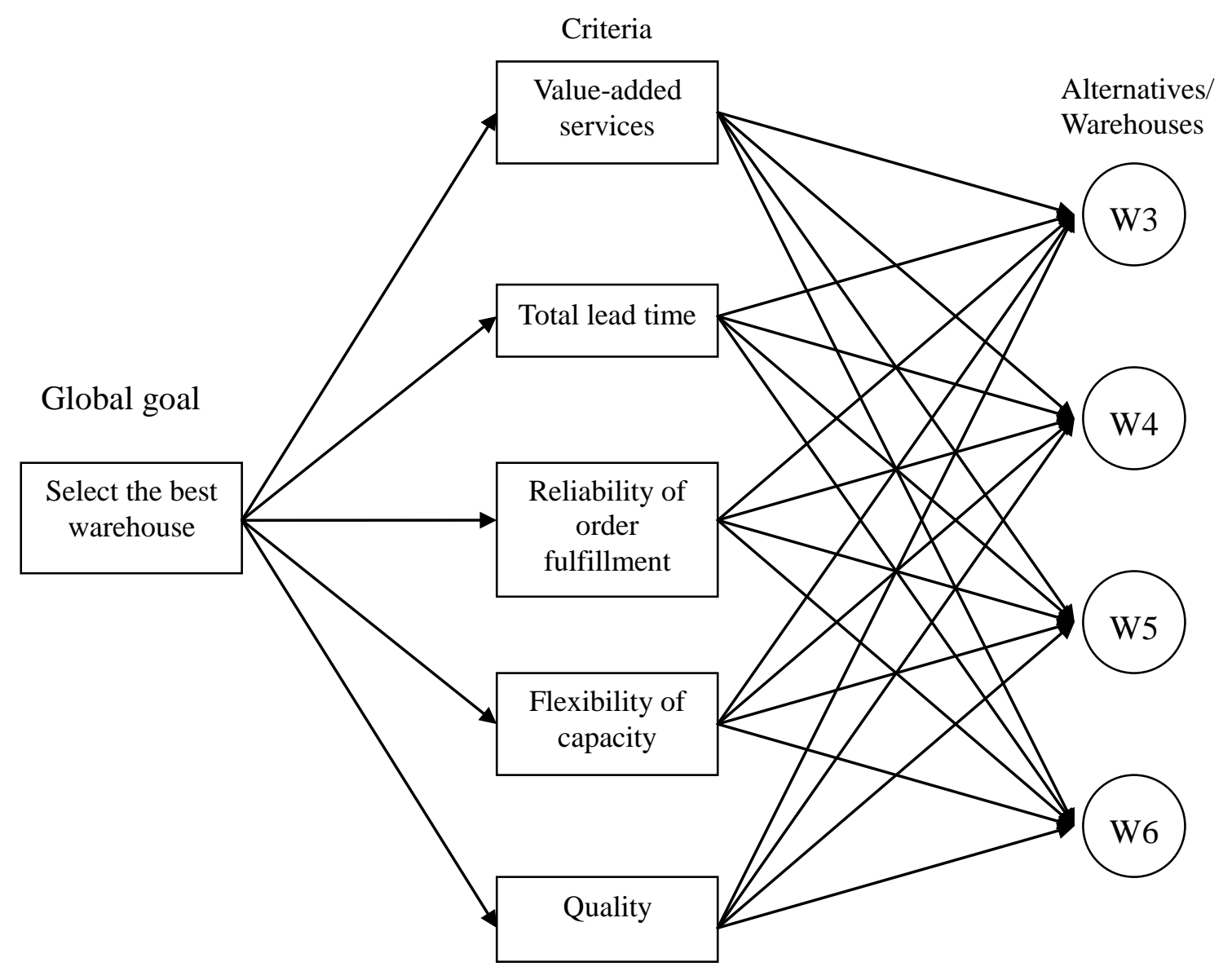

Fig. 3 A hierarchy of the warehouse evaluation problem

In the next step of the decision-making process, weighting of all criteria and scores of alternative warehouses are derived from fuzzy pairwise comparison matrices of the equation (4-8). In this example, we suppose that all pairwise comparison judgments are represented as fuzzy triangular numbers $\tilde{a}_{i j}=\left(l_{i j}, m_{i j}, u_{i j}\right)$, such that $u_{i j}>m_{i j}>l_{i j}$.

After constructing the hierarchy and obtaining the related information of the five criteria and the alternative warehouses, two criteria are compared at a time with respect to the global goal by using the linguistic variables and their corresponding triangle fuzzy number scale (see detail in Table 3 and Table 4). The fuzzy comparison judgments with respect to the global goal are shown in Table 6. 
Table 6 Fuzzy pairwise comparisons of criteria and priorities of criteria with respect to global goal

\begin{tabular}{ccccccc}
\hline Global Goal & C1 & C2 & C3 & C4 & C5 & Priorities \\
\hline C1 & $(1,1,1)$ & $(0.286,0.333$, & $(0.286,0.333$, & $(2.5,3,3.5)$ & $(0.4,0.5$, & 0.124 \\
& & $0.444)$ & $0.444)$ & $0.667)$ & 0.316 \\
C2 & $(2.5,3,3.5)$ & $(1,1,1)$ & $(1,1,1)$ & $(3.5,4,4.5)$ & $(1.5,2,2.5)$ & 0.316 \\
C3 & $(2.5,3,3.5)$ & $(1,1,1)$ & $(1,1,1)$ & $(3.5,4,4.5)$ & $(1.5,2,2.5)$ & 0.317 \\
C4 & $(0.286,0.333$, & $(0.222,0.25$, & $(0.222,0.25$, & $(1,1,1)$ & $(0.286,0.333$, & 0.064 \\
& $0.4)$ & $0.286)$ & $0.286)$ & & $0.4)$ & \\
C5 & $(1.5,2,2.5)$ & $(0.4,0.5,0.667)$ & $(0.4,0.5$, & $(2.5,3,3.5)$ & $(1,1,1)$ & 0.182 \\
CR & & $0.667)$ & & & 0.033 \\
& & & & & & \\
\hline
\end{tabular}

C1: Value-added services; C2: Total lead time; C3: Reliability of order fulfillment; C4: Flexibility of capacity; C5: Quality.

To obtain the crisp weightings of these criteria, equations from (4-9) to (4-14) are used. The local weightings (priorities) of the five criteria and the $C R$ of the pairwise comparison matrix in Table 6 thus obtained are:

$$
W_{c 1}=0.124, W_{c 2}=0.316, W_{c 3}=0.317, W_{c 4}=0.064, W_{c 5}=0.182 \text { and } C R=0.033 \text {. }
$$

Since $C R<0.1$, all initial fuzzy judgments are approximately satisfied. For example, the desired comparison ratio between "C3" and “C1", as seen in Table 6 is about 3, whereas the corresponding solution ratio is $W_{c 3} / W_{c 1}=2.56$. Therefore, all comparison judgments are equally satisfied with the solution.

Once the pairwise comparisons have been made for the five criteria, the four possible warehouses are further compared with respect to the above five criteria at a time. The corresponding fuzzy pairwise comparison matrices are shown in Table 7.

By applying the same method as above, the scores (priorities) of the alternative warehouses with respect to all criteria are derived, which are also shown in the last column of Table 7. The judgments are all acceptable because the CRs are all below the maximum 0.10 level. 
Table 7 Priorities of alternative warehouses with respect to criteria

\begin{tabular}{|c|c|c|c|c|c|}
\hline & W3 & W4 & W5 & W6 & Priorities \\
\hline \multicolumn{6}{|c|}{ (C1: Value-added services) } \\
\hline W3 & $(1,1,1)$ & $(0.4,0.5,0.667)$ & $(0.4,0.5,0.667)$ & $(0.286,0.333,0.4)$ & 0.121 \\
\hline W4 & $(1.5,2,2.5)$ & $(1,1,1)$ & $(1,1,1)$ & $(0.5,0.5,0.5)$ & 0.237 \\
\hline W5 & $(1.5,2,2.5)$ & $(1,1,1)$ & $(1,1,1)$ & $(0.5,0.5,0.5)$ & 0.237 \\
\hline W6 & $(2.5,3,3.5)$ & $(2,2,2)$ & $(2,2,2)$ & $(1,1,1)$ & 0.405 \\
\hline$C R$ & & & & & 0.017 \\
\hline \multicolumn{6}{|c|}{ (C2: Total lead time) } \\
\hline W3 & $(1,1,1)$ & $(2.5,3,3.5)$ & $(2.5,3,3.5)$ & $(4.5,5,5.5)$ & 0.518 \\
\hline W4 & $(0.286,0.333,0.4)$ & $(1,1,1)$ & $(1,1,1)$ & $(3.5,4,4.5)$ & 0.218 \\
\hline W5 & $(0.286,0.333,0.4)$ & $(1,1,1)$ & $(1,1,1)$ & $(3,3,3)$ & 0.198 \\
\hline W6 & $(0.182,0.2,0.222)$ & $(0.222,0.25,0.286)$ & $(0.333,0.333,0.333)$ & $(1,1,1)$ & 0.074 \\
\hline$C R$ & & & & & 0.029 \\
\hline \multicolumn{6}{|c|}{ (C3: Reliability of order fulfillment) } \\
\hline W3 & $(1,1,1)$ & $(2.5,3,3.5)$ & $(0.4,0.5,0.667)$ & $(0.286,0.333,0.4)$ & 0.472 \\
\hline W4 & $(0.286,0.333,0.4)$ & $(1,1,1)$ & $(0.5,0.5,0.5)$ & $(2,2,2)$ & 0.162 \\
\hline W5 & $(0.5,0.5,0.5)$ & $(2,2,2)$ & $(1,1,1)$ & $(2.5,3,3.5)$ & 0.278 \\
\hline W6 & $(0.2,0.25,0.286$ & $(0.5,0.5,0.5)$ & $(0.286,0.333,0.4)$ & $(1,1,1)$ & 0.096 \\
\hline$C R$ & & & & & 0.017 \\
\hline \multicolumn{6}{|c|}{ (C4: Flexibility of capacity) } \\
\hline W1 & $(1,1,1)$ & $(0.286,0.333,0.4)$ & $(0.5,0.5,0.5)$ & $(0.182,0.2,0.222)$ & 0.087 \\
\hline W2 & $(2.5,3,3.5)$ & $(1,1,1)$ & $(2.5,3,3.5)$ & $(0.5,0.5,0.5)$ & 0.301 \\
\hline W3 & $(2,2,2)$ & $(0.286,0.333,0.4)$ & $(1,1,1)$ & $(0.286,0.333,0.4)$ & 0.144 \\
\hline W4 & $(4.5,5,5.5)$ & $(2,2,2)$ & $(2.5,3,3.5)$ & $(1,1,1)$ & 0.475 \\
\hline$C R$ & & & & & 0.028 \\
\hline \multicolumn{6}{|c|}{ (C5: Quality) } \\
\hline W3 & $(1,1,1)$ & $(3.5,4,4.5)$ & $(2,2,2)$ & $(2.5,3,3.5)$ & 0.473 \\
\hline W4 & $(0.222,0.25,0.286)$ & $(1,1,1)$ & $(0.286,0.333,0.4)$ & $(1,1,1)$ & 0.121 \\
\hline W5 & $(0.5,0.5,0.5)$ & $(2.5,3,3.5)$ & $(1,1,1)$ & $(2,2,2)$ & 0.282 \\
\hline W6 & $(0.286,0.333,0.4)$ & $(1,1,1)$ & $(0.5,0.5,0.5)$ & $(1,1,1)$ & 0.130 \\
\hline$C R$ & & & & & 0.021 \\
\hline
\end{tabular}

After completion of all pairwise comparisons, the global weightings of the four warehouses, calculated by the AHP aggregation rule, are represented in the second last row of Table 8. The aggregated weightings show that warehouse 3 or W3 has the best overall performance because it scores the highest weighting $\left(w p_{3}=0.420\right)$, followed by W5 $\left(w p_{5}=\right.$ $0.241)$, W4 $\left(w p_{4}=0.191\right)$, and W6 $\left(w p_{6}=0.157\right)$. 
Table 8 Data analysis for the warehouse evaluation problem

\begin{tabular}{lccccc}
\hline & & \multicolumn{4}{c}{ Alternatives } \\
\cline { 3 - 6 } Criteria & Weights & W3 & W4 & W5 & W6 \\
\hline Value-added services & 0.124 & 0.121 & 0.237 & 0.237 & 0.405 \\
Total lead time & 0.316 & 0.518 & 0.218 & 0.198 & 0.074 \\
Reliability of order fulfillment & 0.317 & 0.472 & 0.162 & 0.278 & 0.096 \\
Flexibility of capacity & 0.064 & 0.087 & 0.301 & 0.144 & 0.475 \\
Quality & 0.182 & 0.473 & 0.121 & 0.282 & 0.130 \\
& Overall weightings & 0.420 & 0.191 & 0.241 & 0.157 \\
& Ranking & 1 st & 3rd & 2nd & 4th \\
\hline
\end{tabular}

Using the equation (3-14), the weighting factors for warehouse $i$ (i.e., $w f_{i}$ ) can be computed. That is: $w f_{3}=0.196, w f_{4}=0.256, w f_{5}=0.273, w f_{6}=0.284$.

\section{Result analysis of the illustrative example}

After obtaining the weighting factors of the alternative warehouses, Model 3.1 and Model 3.2 are employed to calculate the minimum cost and the minimum weighted logistics cost of the multi-criteria transshipment problem, respectively. The remaining necessary resource data of this illustrative example are represented in Figure 2 and Table 9, provided by our collaborator.

Table 9 Resource data for the transshipment model

\begin{tabular}{cccccc}
\hline Warehouse, $i$ & $\begin{array}{c}\text { Maximum } \\
\text { throughput of } \\
\text { warehouse } i\end{array}$ & $\begin{array}{c}\text { Minimum } \\
\text { throughput of } \\
\text { warehouse } i\end{array}$ & $\begin{array}{c}\text { Unit holding } \\
\text { cost (yuan) }\end{array}$ & $\begin{array}{c}\text { Fixed setup } \\
\text { cost (yuan) }\end{array}$ & $\begin{array}{c}\text { Penalty cost } \\
\text { (yuan) }\end{array}$ \\
\hline 3 & $Q_{i}$ & $q_{i}$ & $h c_{i}$ & $f c_{i}$ & $p c_{i}$ \\
\hline 4 & 30000 & 5000 & 6 & 25000 & 7000 \\
5 & 20000 & 5000 & 5 & 20000 & 6000 \\
6 & 20000 & 5000 & 4 & 15000 & 4000 \\
\hline
\end{tabular}

Arbitrary large number, $M=100000$.

Two analyses have been made on the problem. First, model 3.1 with the objective of minimizing the total transportation cost was focused, in which the weighting factors (i.e., $w f_{i}$ ) were not included. The optimal solution, solved using LINDO, of the model without incorporating the weighting factors is shown in Table 10. Two warehouses were selected in the transshipment network, including W5 and W6. The total cost spent in setting up these two warehouses, holding inventory in the warehouses, and delivering products from the warehouses to their assigned customers is $¥ 779,400$ without incurring any penalty cost. 
Table 10 Optimal solution of Model 3.1

\begin{tabular}{|c|c|c|c|c|c|c|c|c|c|}
\hline \multirow[b]{3}{*}{$i$} & \multicolumn{9}{|c|}{ Allocation of products, $x_{i j}$} \\
\hline & \multicolumn{9}{|c|}{$j$} \\
\hline & W3 & W4 & W5 & W6 & C7 & C8 & 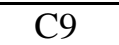 & C10 & C11 \\
\hline$\overline{\mathrm{P} 1}$ & - & - & 26400 & - & - & - & - & - & - \\
\hline $\mathrm{P} 2$ & - & - & 5600 & 12000 & - & - & - & - & - \\
\hline W3 & - & - & - & - & - & - & - & - & - \\
\hline W4 & - & - & - & - & - & - & - & - & - \\
\hline W5 & - & - & - & - & - & 8000 & 10000 & 8000 & 6000 \\
\hline W6 & - & - & - & - & 12000 & - & - & - & - \\
\hline
\end{tabular}

To increase the company's competitiveness, the multi-criteria transshipment model 3.2 is used as the second analysis. In the contemporary supply chain, an optimal distribution network means that the total cost is minimized and also the customer satisfaction level is maximized. To achieve this goal, the fuzzy AHP priorities of warehouses transformed into the weighting factors were included in the model. Table 11 illustrates the optimal solution of the multi-criteria model. Two best warehouses were selected in the transshipment network, including W3 and W5, and the total logistics cost spent is $¥ 825,200$.

Table 11 Optimal solution of Model 3.2

\begin{tabular}{cccccccccc}
\hline & \multicolumn{8}{c}{ Allocation of products, $x_{i j}$} \\
& \multicolumn{8}{c}{$j$} \\
\cline { 2 - 10 } & W3 & W4 & W5 & W6 & C7 & C8 & C9 & C10 & C11 \\
\hline P1 & 26400 & - & - & - & - & - & - & - & - \\
P2 & 1600 & - & 16000 & - & - & - & - & - & - \\
W3 & - & - & - & - & 12000 & - & 10000 & - & 6000 \\
W4 & - & - & - & - & - & - & - & - & - \\
W5 & - & - & - & - & - & 8000 & - & 8000 & - \\
W6 & - & - & - & - & - & - & - & - & - \\
\hline
\end{tabular}

The comparison between fuzzy AHP priority ranking and the optimal solutions of the cost-based and multi-criteria models is summarized in Table 12. 
Table 12 Comparison between FAHP priority ranking and the solutions of Model 3.1 and Model 3.2

\begin{tabular}{ccccc}
\hline Warehouses & $w p_{i}$ & FAHP priority ranking & Cost-based model & Multi-criteria model \\
\hline 3 & 0.420 & 1st & Not selected & Selected \\
4 & 0.191 & 3rd & Not selected & Not selected \\
5 & 0.241 & 2nd & Selected & Selected \\
6 & 0.157 & 4th & Selected & Not selected \\
\hline
\end{tabular}

From the above analysis, although the total cost of the optimal solution of Model 3.2 is slightly higher than that of Model 3.1, ¥825,200 vs. ¥779,400 (about 6\% increase in cost), the summation of fuzzy AHP priorities of the selected warehouses is increased by about 66\%, 0.661 vs. 0.398 . This can definitely enhance the competitiveness of the company and also the satisfaction level of its customers.

For the first analysis, although it can be guaranteed that the total cost is lower, an acceptable customer service level may not be achieved. The lower summation of fuzzy AHP priorities of the selected warehouses means that some customer service elements are not in a favorable condition, for example long lead time, inaccurate order fulfillment, poor quality, low flexibility, and lack of value-added services. As a result, the satisfaction level of its customers will be decreased and most important, the chance of repeating orders may be affected.

\section{Conclusions}

This paper developed a holistic approach to solve the contemporary transshipment problem. The key value of this research is in a methodology for integrating quantitative and qualitative analyses under fuzzy environment, in order to maximize the benefits of deliverer and customers. The method is tested by a case company in China and the case company indicated that the FAHP-based ILP model have been helpful in transforming its operations towards a service dominant supply chain.

The FAHP-based ILP model synthesizes the advantages of the previous methods (see in Table 1) while overcoming their drawbacks. In this method, the fuzzy AHP was used to determine the relative importance weighting of alternative transshipment points with respect to the five evaluation criteria. The relative importance weightings or the fuzzy AHP priorities represent the ability of the alternatives in maximizing the satisfaction level of deliverer and customer. After assigning the priorities of the alternatives, the model incorporating the weighting factors transformed from the fuzzy AHP priorities was formulated to select the best 
alternatives at the lowest possible logistics cost. The major advantages of this approach are that both quantitative and qualitative factors are considered simultaneously and also the viewpoints of the deliverers and customers are focused. Therefore, it is believed that this approach should be more useful and applicable than the traditional optimization techniques.

Limitations of the reported research lie in that only one case company was studied. Considering the generalization of the research findings and the complexity of the transshipment service network, more cases across a broader range of industry sectors are necessary to further enhance the validity of the research output.

\section{Acknowledgements}

The authors would like to express sincere gratitude to our collaborated company whose name unfortunately cannot be revealed because of the confidentiality agreement between us, who provided valuable time and information for this research. The authors are also indebted to the reviewers for their constructive comments and suggestions which enabled the improvement of the quality of the present study. 


\section{References}

1. Ballou R.H.(2004), Business logistics/supply chain management: planning, organizing, and controlling the supply chain (5th Edition), Pearson Prentice Hall, New Jersey.

2. Bellman R.E. and Zadeh L.A. (1970), "Decision-making in a fuzzy environment”, Management Science, Vol.17 No.4, pp.141-164.

3. Bertolini, M. and Bevilacqu, M. (2006), "A combined goal programming-AHP approach to maintenance selection problem”, Reliability Engineering \& System Safety, Vol. 91, No.7, pp.839-848.

4. Boender C.G.E., Graan J.G. de and Lootsma F.A. (1989), "Multicriteria decision analysis with fuzzy pairwise comparisons”, Fuzzy Sets System. Vol.29, pp.133-143.

5. Chang D.A. (1996), “Application of the extent analysis method on fuzzy AHP”, European Journal of Operational Research, Vol. 95, pp.649-655.

6. Chan, F. T. S. and Chung, S. H. (2004a), "Multi-criteria genetic optimization for distribution network problems”, International Journal of Advanced Manufacturing Technology, Vol.24, pp. 517-532.

7. Chan, F. T. S. and Chung, S. H. (2004b), “A multi-criterion genetic algorithm for order distribution in demand driven supply chain”, International Journal of Computer Integrated Manufacturing, Vol. 17 No.17, pp. 339-351.

8. Chan, F. T. S. and Chung, S. H. (2005), "Multicriterion genetic optimization for due date assigned distribution network problems”, Decision Support Systems, Vol.39, pp.661-675.

9. Chan, F. T. S., Chung, S. H. and Wadhwa, S. (2004), “A heuristic methodology for order distribution in a demand driven collaborative supply chain”, International Journal of Production Research, Vol.42, pp.1-19.

10. Chan, F. T. S., Chung, S. H. and Wadhwa, S. (2005), "A hybrid genetic algorithm for production and distribution”, Omega, Vol.33, pp.345-355.

11. Chan, F. T. S., Chung, S. H., \& Choy, K. L. (2006), “Optimization of order fulfillment in distribution network problems”, Journal of Intelligent Manufacturing, Vol.17, pp. 307-319.

12. Chan, F.T.S., Kumar, N. and Choy, K.L. (2007), "Decision-making approach for the distribution centre location problem in a supply chain network using the fuzzy-based hierarchical concept”, Proceedings of the Institution of Mechanical Engineers, Part B: Journal of Engineering Manufacture. Vol. 221 No. 4, pp.725-739.

13. Chang, D.Y. (1996). “Applications of the extent analysis method on fuzzy AHP”, European Journal of Operational Research, Vol. 95, pp.649-655.

14. Chen C.T.(2000), "A fuzzy MCDM method based on interval analysis for solving plant location selection problem”, Journal of the Chinese Institute of Industrial Engineers, Vol. 17 No.1, pp.111-120.

15. Chou C.C. (2007), “A fuzzy MCDM method for solving marine transshipment container port selection problems”, Applied Mathematics and Computation, Vol.186, pp.435-444.

16. Chou C.C. (2010), "Application of FMCDM model to selecting the hub location in the marine transportation: A case study in southeastern Asia”, Mathematical and Computer Modelling, Vol.51, 
pp.791-801.

17. Chou, S., Chang, Y. and Shen, C. (2008), "A fuzzy simple additive weighting system under group decision-making for facility location selection with objective/subjective attributes”, European Journal of Operational Research, Vol.189 No.1, pp.132-145.

18. Driankov D., Hellendoorn H. and Reinfrank M. (1996), An introduction to fuzzy control, 2nd rev. ed., Springer-verlag Berlin Heidelberg, New York.

19. Farahani, R. Z. and Asgari, N.(2007), "Combination of MCDM and covering techniques in a hierarchical model for facility location”, European Journal of Operational Research, Vol. 176, pp. 1839-1858.

20. Gogus O. and Boucher T. (1997), "A consistency test for rational weights in multi-criterion decision analysis with fuzzy pairwise comparisons”, Fuzzy Sets System. Vol.86, pp.129-138.

21. Ho, W. (2008). "Integrated analytic hierarchy process and its applications - a literature review". European Journal of Operational Research, Vol.186, pp.211-228.

22. Ho, W. and Emrouznejad, A.(2009), "Multi-criteria logistics distribution network design using SAS/OR”, Expert Systems with Applications, Vol.36, pp.7288-7298.

23. Kengpol, A. (2008), "Design of a decision support system to evaluate logistics distribution network in Greater Mekong Subregion Countries”, International Journal of Production Economics, Vol. 115 No. 2, pp.388-399

24. Kengpol, A., Tuominen, M., (2006), “A framework for group decision support systems: An application in the evaluation of information technology for logistics firms”, International Journal of Production Economics, Vol.101, pp.159-171.

25. Korpela, J. and Tuominen, M. (1996), “A decision aid in warehouse site selection”, International Journal of Production Economics Vol.45, pp.169-188.

26. Korpela, J. and Lehmusvaara, A. (1999), “A customer oriented approach to warehouse network evaluation and design”, International Journal of Production Economics, Vol. 59 No. 1-3, pp. 135-146.

27. Korpela J., Lehmusvaara, A. and Tuominen, M. (2001a), "Customer service based design of the supply chain”, International Journal of Production Economics, Vol. 69 No. 2, pp. 193-204.

28. Korpela, J., Kyläheiko, K., Lehmusvaara, A., and Tuominen, M. (2001b), “The effect of ecological factors on distribution network evaluation”, International Journal of Logistics: Research and Applications, Vol. 4 No. 2, pp.257-269.

29. Korpela, J., Kyläheiko, K., Lehmusvaara, A., and Tuominen, M. (2002), “An analytic approach to production capacity allocation and supply chain design”, International Journal of Production Economics, Vol.78, pp. 187-195.

30. Kumar A., Kaur A. and Gupta A.(2011), "Fuzzy Linear Programming Approach for Solving Fuzzy Transportation Problems with Transshipment”, Journal of Math Model Algorithm, Vol 10, pp.163-180.

31. Liang G.S. and Wang, M.J.(1991), "A fuzzy multi-criteria decision-making method for facility site selection”, International Journal of Production Research, Vol.29, pp.2313-2330. 
32. Malchow, M.B. and Kanafani, A.(2004), “A disaggregate analysis of port selection”, Transportation Research Part E: Logistics and Transportation Review, Vol. 40, No.4, pp.317-337.

33. Meixner O. (2009), "Fuzzy group decision analysis and its application for the evaluation of energy sources", the Proceedings of the 10th International Symposium on the Analytic Hierarchy/Network Process, Pittsburtgh/PA, USA, University of Pittsburgh.

34. Mikhailov L. and Tsvetinov P. (2004), "Evaluation of services using a fuzzy analytic hierarchy process”, Applied Soft Computing, Vol.5, pp. 23-33.

35. Önüt S. and Soner S. (2008), "Transshipment site selection using the AHP and TOPSIS approaches under fuzzy environment”, Waste Management, Vol.28, pp.1552-1559.

36. Saaty T.L.(1980), The Analytic Hierarchy Process, McGraw-Hill, New York.

37. Saaty, T.L.(1990), Decision Making: The Analytic Hierarchy Process, RWS Publications, Pittsburgh.

38. Saaty, T.L.(1995), Decision Making for Leaders: The Analytic Hierarchy Process for Decisions in a Complex World (1995/1996 ed.), RWS Publications, Pittsburgh.

39. Sharma D.K. and Jana R.K.(2009), “A hybrid genetic algorithm model for transshipment management decisions”, International Journal of Production Economics, Vol.122, pp. 703-713.

40. Tabari, M., Kaboli, A., Aryanezhad, M.B., Shahanaghi, K. and Siadat, A. (2008), “A new method for location selection: A hybrid analysis”, Applied Mathematics and Computation, Vol.206 No. 2, pp.598-606.

41. Winston W. L. (2003), Operations Research: Applications \& Algorithms (4th edition), Duxbury Press.

42. Xu R. (2000), "Fuzzy least square priority method in the analytic hierarchy process", Fuzzy Sets System. Vol.112, pp.395-404.

43. Zadeh L.A. (1965), "Fuzzy sets”, Information and Control, Vol.8, pp.338-353. 


\section{University Library}

\section{- M M I N E R VA A gateway to Melbourne's research publications}

Minerva Access is the Institutional Repository of The University of Melbourne

Author/s:

He, T;Ho, W;Man, CLK;Xu, X

Title:

A fuzzy AHP based integer linear programming model for the multi-criteria transshipment problem

Date:

2012

Citation:

He, T., Ho, W., Man, C. L. K. \& Xu, X. (2012). A fuzzy AHP based integer linear programming model for the multi-criteria transshipment problem. The International Journal of Logistics Management, 23 (1), pp.159-179. https://doi.org/10.1108/09574091211226975.

Persistent Link:

http://hdl.handle.net/11343/118657 